\title{
Protrusion of Implant after Surgical Wall Reconstruction due to Temporomandibular Joint Herniation
}

\author{
Beom Mo Koo, Moon Seung Baeg, Seong Kyu Moon, and Hyun Sang Cho $\mathbb{D}$ \\ Department of Otorhinolaryngology-Head and Neck Surgery, Veterans Health Service Medical Center, Seoul, Korea \\ 턱관절 탈출에 대한 수술적 재건 후 이식물의 돌출 \\ 구범모 · 백문승 · 문성규 · 조현상 \\ 중앙보훈병원 이비인후-두경부외과
}

Received May 18, 2020

Revised July 14, 2020

Accepted July 16, 2020

Address for correspondence

Hyun Sang Cho, MD

Department of Otorhinolaryngology-

Head and Neck Surgery,

Veterans Health Service

Medical Center,

53 Jinhwangdo-ro 61-gil,

Gangdong-gu, Seoul 05368, Korea

Tel $+82-2-2225-4369$

Fax $+82-2-2225-1385$

E-mailent-cho@nate.com
Herniation of the temporomandibular joint (TMJ) into the external auditory canal is rare as TMJ and external auditory canal are separated by an anterior bony wall of external auditory canal. The bony defect of the anterior external auditory canal can be caused by trauma, otologic procedure, neoplasm, inflammation and a rare congenital bony defect. Conservative treatment is available if the severity of the symptom is mild or asymptomatic. However, surgical procedure is considered if the patient experiences severe distress. There have been no reported cases of surgical-related complications and recurrence during postoperative follow-up period. Herein we report the very first case of foreign body prolapse involving herniation from TMJ extending into the external auditory canal.

Korean J Otorhinolaryngol-Head Neck Surg 2021;64(3):183-7

Key Words External auditory canal · Foreign body · Temporomandibular joint.

\section{서 론}

턱관절 구조물의 탈출은 드물게 턱관절와(mandibular fos$\mathrm{sa}$ )의 후벽과 외이도 전벽 사이의 결손과 연관하여 나타날 수 있다.' 이러한 결손은 외상, 감염, 신생물, 염증 등으로 인해 이차적으로 나타날 수도 있고, 매우 드물게 Huschke 공의 지속 개방 상태로 인해 자발적으로 나타날 수도 있다. ${ }^{2)}$ 무증 상이거나 증상이 미약할 경우에는 보존적인 치료가 주를 이 루나 생활의 불편함을 느낄 정도로 증세가 심하게 나타날 경 우에는 턱관절 탈출에 대한 수술적 치료를 시행할 수 있다. ${ }^{3)}$ 최근까지 턱관절 구조물 탈출을 수술적으로 치료하여 보고 한 증례는 영문 문헌상에 28 개에 불과하고 이중 24 개에서 외 이도 골벽 재건 방식으로 수술을 받았으며 수술 이후 경과

This is an Open Access article distributed under the terms of the Creative Commons Attribution Non-Commercial License (https://creativecommons.org/licenses/by-nc/4.0) which permits unrestricted non-commercial use, distribution, and reproduction in any medium, provided the original work is properly cited.
관찰 시기(평균 9.2개월, 0.5 20개월)동안 합병증이 발생한 경우는 없었다. ${ }^{4)}$ 특히, 수술적 치료를 받은 환자들에서 수술 중 사용하였던 외이도 재건용 삽입물과 관련된 합병증이 보 고된 바는 아직 없다. 저자들은 턱관절 탈출에 대한 수술을 시행 받았던 환자에서 갑작스럽게 발생한 심한 이통을 주소 로 내원하여 외이도 내로 관찰되는 이물질을 진단하고 수술 적 치료를 통해 치료한 증례를 문헌 고찰과 함께 보고하고자 한다.

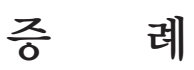

55세 남자 환자가 약 3일 전부터 발생한 좌측 이루를 호소 하며 본원에 첫 내원하였다. 이내시경 검사상 좌측 고막의 발 적 및 비후 소견과 고막 주변으로 미량의 장액성 분비물이 관 찰되는 정도였고, 반대측 고막은 정상이었다. 양측 청력 저하 증상이 1년 전부터 있었으나 이통, 이명 등 다른 이과적 증상 
은 없었으며, 과거력상 13 년 전 타 병원에서 좌측 자발적 턱 관절 조직 탈출에 대해 수술적 치료를 받은 적이 있었다. 좌 측 고막염 및 양측 감각신경성 난청 소견하에 청력검사와 중 이의 병변을 감별하기 위해 측두골 전산화단층촬영도 함께 시행하였고 이용액을 처방하였다.

일주일 후 환자가 재내원하였을 때는 좌측 고막염은 호전 된 상태로 관찰되었고, 순음청력검사에서는 6 분법상 우측 기도 평균 $16 \mathrm{~dB}$, 좌측 기도 평균 $27 \mathrm{~dB}$ 로 좌측 경도난청 소 견을 보였다. 측두골 전산화단층촬영에서는 고막염으로 인해 좌측 고막이 비후 되어 있으나 중이, 내이 및 유양동에 이상 소견 없었고, 턱관절와 후벽에 티타늄 메시(titanium mesh) 로 추정되는 삽입물이 안정적으로 고정되어 있는 상태로 관 찰되었다(Fig. 1A). 환자에게 정기적인 청력검사를 권유하고 치료를 종료하였다.

치료 종료 6 개월이 지난 시기에 환자는 갑작스럽게 발생한 심한 좌측 이통과 이루를 주소로 본원 외래로 재내원하였다. 저작운동 시 좌측 귀에서 덜커덕거리는 소리가 들린다고 하 였고, 단단한 음식을 먹으면 더욱 이통이 악화된다고 호소하 였다. 좌측 외이도에는 점액 농성의 분비물이 관찰되어 우선 균 배양검사 및 항생제 감수성 검사를 시행하였고, 분비물을 흡인 드레싱하였다. 드레싱을 하면서 반투명하고 단단한 이물 질이 좌측 외이도 전벽에서 돌출되어 외이도 안을 차지하고 있는 것을 확인할 수 있었다(Fig. 2A). 외래에서 미세겸자로
제거하려 하였으나 돌출된 이물질은 외이도 전벽에 단단하게 고정이 되어 있었고, 미세도구가 이물질에 닿는 것만으로도 환자는 심한 이통을 호소하여 측두골 전산화단층촬영을 시 행하여 재평가한 후 수술적 치료를 계획하였다.

재시행한 측두골 전산화단층촬영에서 티타늄 매쉬는 이 전과 같이 고정되어 있는 상태였으나, 6개월 전 촬영에서와 달리 좌측 외이도 전벽에서 외이도 안으로 비스듬하게 돌출 되어 있는 $1 \times 12 \times 14 \mathrm{~mm}$ 크기의 연조직음영 이물질이 관찰 되었다(Fig. 1B). 전신마취하에 경외이도 접근으로 이내시경 을 이용하여 외이도 전벽의 이물질이 돌출된 곳에 연장하여 house sickle knife와 미세가위(microscissors)를 이용하여 외이도 피부에 절개선을 가하였다. Weapon을 이용하여 박리 를 진행하면서 단단히 고정이 되어 있던 이물질을 미세겸자로 조심스럽게 제거하였다(Fig. 3). 이물질이 제거된 곳의 외이도 피부 결손 부위는 선상모양이고 범위가 크지 않았으며 안쪽 의 티타늄 매쉬가 안정적으로 고정되어 있었기 때문에 추가 적인 외이도벽 재건을 하지 않았다. 외이도를 무피로신(mupirocin) 연고를 묻힌 거즈로 패킹을 한 후 수술을 마쳤다.

수술 직후 환자는 이통이 감소하였고, 술후 2주째 외이도 내 거즈를 제거하였다. 술후 2 년까지의 추적 관찰에서도 이 통이 재발하지 않았고, 외이도 내에 추가적인 합병증이나 재 발은 나타나지 않았다(Fig. 2B).
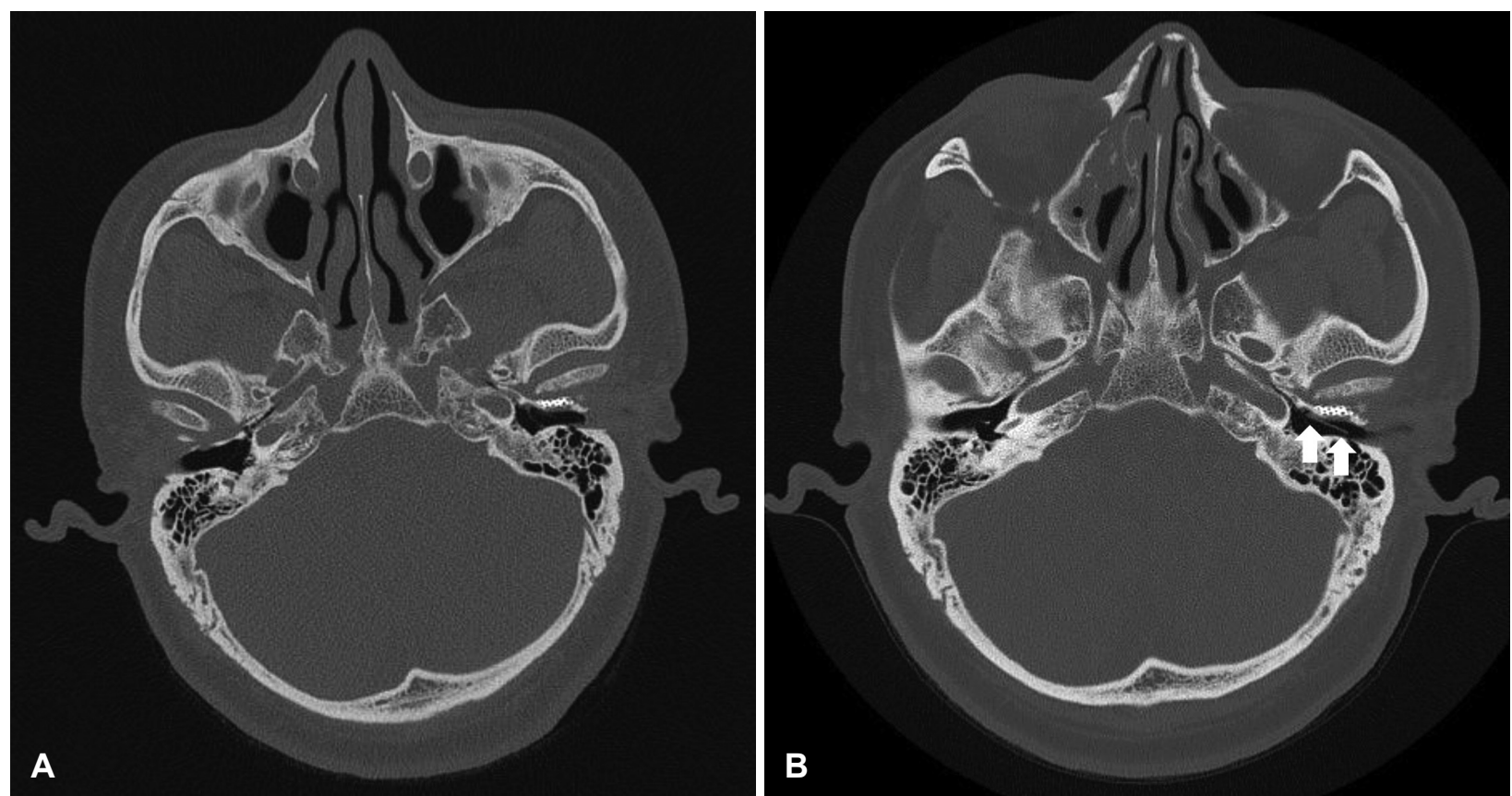

Fig. 1. Preoperative temporal bone CT scan before and after protrusion of foreign material. Axial image of computed tomogram shows left tympanic membrane is diffusely thickened from myringitis and well-positioned titanium mesh under anterior wall of external auditory canal (A). A few months later, axial image of computed tomogram shows a $1 \times 12 \times 14 \mathrm{~mm}$ sized foreign body (arrows) is observed, which obliquely protrudes from anterior wall of the ear canal into the left external auditory canal (B). 

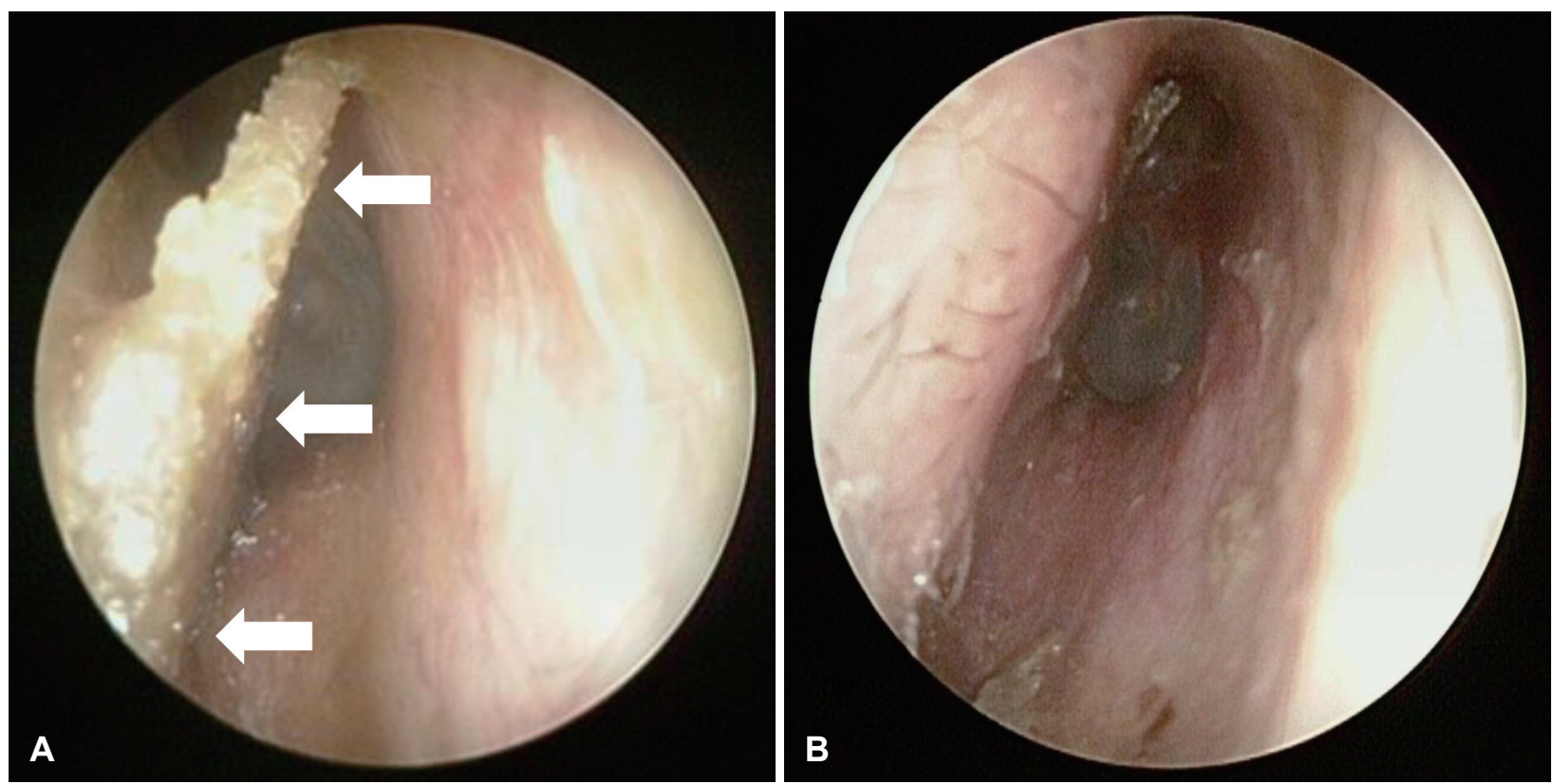

Fig. 2. Preoperative oto-endoscopic evaluation and postoperative states at 24 months follow-up visit. Preoperative otoendoscopic finding shows protruding foreign body (arrows) on anterior wall of left external auditory canal (A). Otoendoscopic finding at 24 months after surgery shows there is no evidence of local lesion in anterior portion of medial side of the external auditory canal $(B)$.

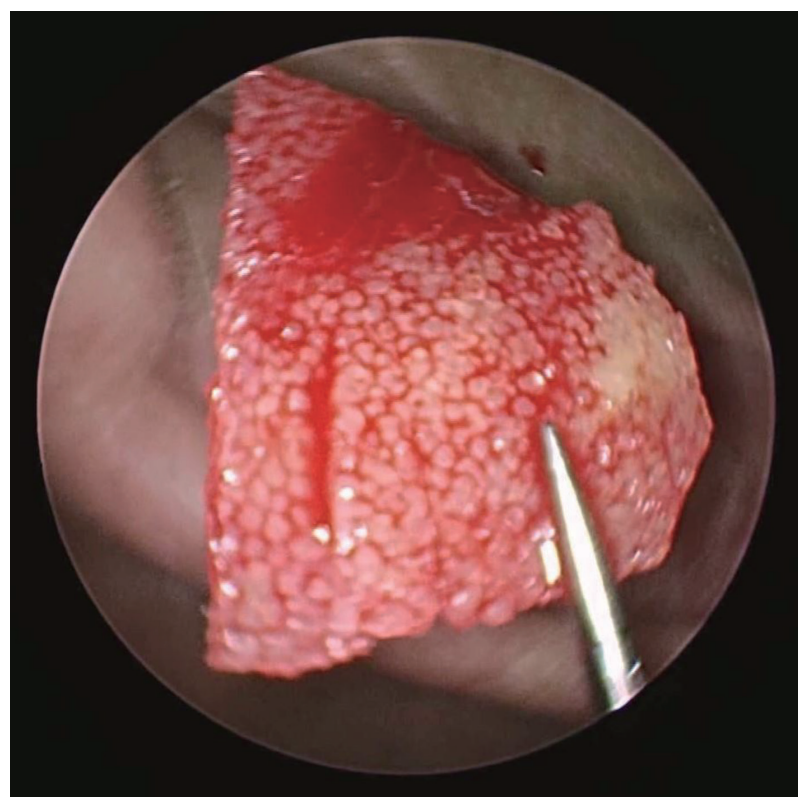

Fig. 3. Otoendoscopic surgical finding shows $1 \times 12 \times 14 \mathrm{~mm}$ sized plastic-like material was identified after removal of foreign body in the left external auditory canal.

\section{고 찰}

턱관절 구조물의 외이도 내 탈출은 이과적 수술, 측두골 골절, 종양, 턱관절의 류마티스 관절염, 악성외이도염 등에서 드물게 나타날 수 있고, 자발적인 턱관절 조직 탈출은 매우 드물게 관찰되곤 한다. ${ }^{5)}$ 측두골의 고실부 발생 과정을 살펴보 면 출생 시에는 융합이 완성되지 않은 상태로 Huschke 공을
형성하게 되며 만 5세가 되면 융합이 완성되어 막히게 되지 만, 성인이 된 후에도 Huschke 공이 완전히 막히지 않는 경 우가 있으며 이러한 경우 외이도 내로 턱관절 조직의 돌출을 초래할 수 있다고 알려져 있다. ${ }^{6}$

증상은 무증상부터 비특이적인 이충만감, 이통, 턱관절 통 증, 저작시 클릭성 이명, 이루 등이 나타날 수 있다. 2.7) 진단은 이내시경 검사와 같은 임상적인 이학적 검사와 측두골 전산 화단층촬영으로 할 수 있고, 탈출은 저작운동에 의해 확인이 가능하여 입을 다물 때 외이도 전벽의 돌출, 입을 벌릴 때 함 몰되는 소견을 관찰할 수 있다고 알려져 있다. ${ }^{8)}$

우연히 발견되거나 증상이 없는 경우에는 특별한 치료 없 이 경과 관찰을 하지만, 심한 증상을 유발하는 경우에는 보 존적 치료 및 수술적 치료를 시행할 수 있으며, 수술적 치료 는 탈출 조직의 복원 및 외이도 결손 부위를 막아 재건하는 방법이다. ${ }^{29)}$ 본 증례의 환자는 자발적인 턱관절 조직 탈출에 의한 심한 이명으로 타 병원에서 13년 전에 외이도 결손 부 위를 막는 수술적 치료를 받았으며 이후 별다른 합병증 없이 지냈었다.

저자는 2000년 이후 최근까지 국내외로 보고된 턱관절 구 조물 탈출에 대하여 수술적으로 외이도를 재건한 21예를 분 석하였다(Table 1).,10) 이식물을 외이도 전벽과 턱관절낭 (temporomandibular joint capsule)의 후면 사이에 넣는 방식으 로 골결손 부위를 재건하는 수술법이 주로 시행되고 있다. ${ }^{4)}$ 접근법에 따른 분류로는 전이접근 14예(66.7\%), 이내 접근 4예 (19.0\%), 이개후 접근 3예(14.3\%)로 전이접근이 많았는데, 이는 
시야 확보가 우수하며, 이식물 삽입에 장점이 있기 때문이다. ${ }^{10)}$ 삽입물로는 자가연골 9예(42.9\%), 티타늄 메시 7예(33.3\%), 측두근막 2예(9.6\%), 자가피부이식 2예(9.6\%) 티타늄 미니플 레이트(titanium miniplate)와 함께 폴리에틸렌(polyethylene) 과 폴리프로필렌(polypropylene) 재료를 이식물로 이용한 1예 (4.8\%)로 나타났으며, 모든 증례 보고에서 관찰 기간 동안 삽 입물 탈출이나 재발에 대한 보고는 없었다. ${ }^{4,11}$

본 증례 환자에서 외이도 전벽을 뜷고 단단한 플라스틱 판 이 외이도 내로 돌출하여 있던 것으로 보아, 측두골 전산화 단층촬영상에서 명확히 관찰되는 티타늄 메시 외에도 폴리 에틸렌이나 폴리프로필렌을 함께 이용하여 겹쳐 보완하는 방식으로 결손 부위를 재건하였던 것으로 추정된다.

사람은 씹는 과정 중 개구 및 폐구운동 뿐만 아니라 전방, 후방, 측방 그리고 이들이 조합된 운동까지 수행한다. 또한 회 전운동(rotary movement)과 병진운동(translatory movement)도 하게 된다. 따라서, 턱관절은 이런 운동을 수행할 수 있도록 윤활운동과 경첩운동의 기능을 한다.

본 증례의 환자는 13 년 전 턱관절 돌출에 대한 수술적 치 료를 받은 이후 십수년간에 걸친 저작운동을 포함하는 지속 적인 턱관절 운동으로 인한 삽입물의 반복된 자극으로 인하 여 얇은 외이도 골부에 지나친 인장력이 인가되고, 이로 인하 여 이차적으로 골부결손 부위의 약해진 부분을 통하여 외이 도 밖으로 삽입물이 노출된 것으로 보인다. 턱관절 조직의 외
이도 탈출에 대해 수술적 치료를 받은 환자들 중에는 기간이 지나면서 합병증 발생과 관련하여 지금까지 알려진 바가 없 었고, 특히 이식재료의 탈출은 첫 사례 보고이다. 재료의 크 기가 외이도 결손 부위를 충분히 덮는지, 충분히 막는다면 결손 부위 크기보다 얼마큼의 절제연을 두고 이식물을 재단 하여 사용하는 것이 안전할 것인지에 대해 고려해야 한다. 수술 중 환자의 턱을 개구 및 폐구 움직임으로 이식물의 위 치가 이동하지 않는지 확인하는 것이 위치 선정에 도움을 줄 수 있고, 이동한다면 이식물의 고정을 생각해 볼 수 있겠다. 즉, 치료 계획과 수술 중에도 수술 재료의 적절한 선택과 크기 그리고 위치 선정에 대해 신중히 고려하는 것이 중요하겠다. 그리고 턱관절 탈출 수술 이후 장기간의 추적 관찰이 필요할 수도 있겠다.

티타늄 메시는 얇고 다루기 편하며 삽입하기 용이한 장점 있는데 다른 재료들과 겹쳐서 두껍게 결손 부위를 보강한다 면 턱관절낭과 외이도 전벽에 부담을 줄 수 있다. 제한된 관 절공간 안에서 지속적인 관절운동이 일어나기 때문에 이식 물을 겹치게 하여 보강하는 것은 턱관절 운동에 제한 요소가 될 수 있고 수술 후 이통과 같은 불편감을 유발할 가능성이 있기 때문에 이식물을 두껍게 하지 않는 것도 고려해야 할 부분으로 생각된다.

턱관절 조직의 외이도로의 돌출에 대한 수술이 드물게 시 행되고 있지만, 본 증례의 경우처럼 수술 시 골결손 부위 재

Table 1. Reported 21 cases of wall reconstructions of temporomandibular joint herniation

\begin{tabular}{|c|c|c|c|c|c|c|}
\hline Year & Author & Age & Sex & Site & Approach & Material \\
\hline 2018 & Burlak, et al. ${ }^{12)}$ & 52 & M & $L$ & Postauricular & Tragal cartilage \\
\hline 2017 & Williams, et al. ${ }^{13)}$ & 46 & M & $R$ & Preauricular & Tragal cartilage \\
\hline 2017 & Singh, et al. ${ }^{14)}$ & 35 & M & $R$ & Preauricular & Tragal cartilage \\
\hline 2017 & Ryu, et al. ${ }^{15)}$ & 46 & $M$ & $R$ & Preauricclar & Titanium mesh \\
\hline 2017 & Baxter, et al. ${ }^{16)}$ & 60 & M & $R$ & Postauricular & Tragal cartilage \\
\hline 2016 & Shapiro, et al. ${ }^{17)}$ & 54 & $M$ & L & Preauricular & Temporal fascia \\
\hline \multirow[t]{2}{*}{2016} & Yoo, et al. ${ }^{18)}$ & 66 & $M$ & $R$ & Endaural & Titanium mesh \\
\hline & & 47 & $\mathrm{~F}$ & L & Endaural & Titanium mesh \\
\hline 2015 & Rena, et al. ${ }^{19)}$ & 8 & M & B & Preauricular & Temporal fascia \\
\hline 2013 & Nakasato, et al. ${ }^{20)}$ & 61 & M & $R$ & Postauricular & Auricular cartilage \\
\hline 2012 & Ajduk, et al. ${ }^{21)}$ & 56 & W & $R$ & Preauricular & Tragal cartilage \\
\hline 2011 & Akcam, et al. ${ }^{7)}$ & 48 & $\mathrm{~F}$ & L & Preauricular & Tragal cartilage \\
\hline \multirow[t]{6}{*}{2010} & Park, et al. ${ }^{5)}$ & 54 & M & L & Preauricular & Titanium mesh \\
\hline & & 48 & M & L & Preauricular & Titanium mesh \\
\hline & & 61 & M & L & Endaural & Skin graft \\
\hline & & 56 & M & $R$ & Endaural & Skin graft \\
\hline & & 50 & M & L & Preauricular & Titanium mesh \\
\hline & & 73 & $\mathrm{~F}$ & $R$ & Preauricular & Titanium mesh \\
\hline 2009 & Tan, et al. ${ }^{22)}$ & 53 & $\mathrm{~F}$ & $R$ & Preauricular & Tragal cartilage \\
\hline 2005 & Moriyama, et al. ${ }^{2)}$ & 41 & M & $R$ & Preauricular & Tragal cartilage \\
\hline 2000 & Anand, et al. ${ }^{11)}$ & 51 & $\mathrm{~F}$ & L & Preauricular & Titanium miniplate \\
\hline
\end{tabular}


건에 사용했던 삽입물의 지연성 이탈이 발생할 수도 있음을 염두에 두는 것이 중요하겠다.

\section{Acknowledgments}

None.

\section{Author Contribution}

Conceptualization: Hyun Sang Cho. Writing_-original draft: Beom Mo Koo, Moon Seung Baeg, Seong Kyu Moon. Writing-review \& editing: Hyun Sang Cho.

\section{ORCID}

Hyun Sang Cho https://orcid.org/0000-0003-3411-544X

\section{REFERENCES}

1) Vitale RF, Gonçalez F, Rausis MG. Spontaneous herniation of the temporomandibular joint into the external auditory canal. A case report and literary review. Int Congr 2003;1240:139-43.

2) Moriyama M, Kodama S, Suzuki M. Spontaneous temporomandibular joint herniation into the external auditory canal: A case report and review of the literature. Laryngoscope 2005;115(12):2174-7.

3) Song JN, Shim MJ, Yeo SW, Park SN. Objective tinnitus due to spontaneous temporomandibular joint herniation treated by reconstruction with titanium mesh. Korean J OtorhinolaryngolHead Neck Surg 2014;57(1):46-9.

4) Jo YS, Cheong TY, Han BH, Lee JM, Kim SH, Moon IS. Temporomandibular joint herniation: Review of the literature. Otol Neurotol 2020;41(1):e1-6.

5) Park YH, Kim HJ, Park MH. Temporomandibular joint herniation into the external auditory canal. Laryngoscope 2010;120(11):2284-8.

6) Selesnick SH, Carew JF, DiBartolomeo JR. Herniation of the temporomandibular joint into the external auditory canal: A complication of otologic surgery. Am J Otol 1995;16(6):751-7.

7) Akcam T, Hidir Y, Ilica AT, Kilic E, Sencimen M. Temporomandibular joint herniation into the external ear canal through foramen of Huschke. Auris Nasus Larynx 2011;38(5):646-9.

8) Lee CK, Park KH. Spontaneous temporomandibular joint herniation. Otolaryngol Head Neck Surg 2011;144(2):292-3.

9) Ha SH, Oh JI, Park MI, Kim CW. A case of spontaneous temporomandibular joint herniation into the external auditory canal. Korean J Otorhinolaryngol-Head Neck Surg 2010;53(3):175-8.
10) Lee JK, Lee BS, Jang SK, Park SK. A case of bony defect of the anterior external auditory canal wall causing ear fullness. Korean J Otorhinolaryngol-Head Neck Surg 2020;63(3):129-33.

11) Anand VT, Latif MA, Smith WP. Defects of the external auditory canal: A new reconstruction technique. J Laryngol Otol 2000; 114(4):279-82.

12) Burlak K, So TY, Maclaurin WA, Dixon AF. Foramen tympanicum with symptomatic temporomandibular joint herniation. Radiol Case Rep 2018;13(4):822-4.

13) Williams RA, Jackler RK, Corrales CE. Benign temporomandibular joint lesions presenting as masses in the external auditory canal. Otol Neurotol 2017;38(4):563-71.

14) Singh I, Jain A, Prasad P, Rajpurohit P. Spontaneous temporomandibular joint herniation: A rare case. Oral Maxillofac Surg 2017;21(1):87-90.

15) Ryu KH, Baek HJ, Hur DG. Spontaneous temporomandibular joint herniation into the external auditory canal through a patent foramen of Huschke: A case report. Ann Med Surg (Lond) 2017;18:33-5.

16) Baxter MC, Keller M, Shah A, Wise S. Surgical emphysema following canalplasty for aural exostoses. Otol Neurotol 2017;38(8): 1174-7.

17) Shapiro MC, Osborn T. Temporoparietal fascia flap and total temporomandibular joint replacement for the management of patent foramen of Huschke. Int J Oral Maxillofac Surg 2016;45(8): 1023-6.

18) Yoo MH, Park JW, Lee HS, Yang CJ, Park HJ. Repair of the foramen of Huschke using an extended endaural approach. Laryngoscope 2016;126(9):2137-9.

19) Rana K, Rathore PK, Raj A, Meher R, Wadhwa V, Prakash A, et al. Bilateral spontaneous salivary otorrhoea: Case report and a review of the literature. Int J Pediatr Otorhinolaryngol 2015;79(10): 1774-7.

20) Nakasato T, Nakayama T, Kikuchi K, Ehara S, Ohtsuka H, Fukuda $\mathrm{K}$, et al. Spontaneous temporomandibular joint herniation into the external auditory canal through a persistent foramen tympanicum (Huschke): Radiographic features. J Comput Assist Tomogr 2013; 37(1):111-3.

21) Ajduk J, Ries M, Vagic D, Batos-Tripalo A. Temporomandibular joint fistula into the external ear canal. J Laryngol Otol 2012; 126(8):837-9.

22) Tan NC, Wilson A, Buckland J. Herniation of the temporomandibular joint into the external auditory meatus secondary to benign necrotising otitis externa. Br J Oral Maxillofac Surg 2009;47(2): $135-7$. 